Open Access

\title{
A review of Chinese ethnology in the past hundred years and its summary in the new era
}

Shengmin Yang

Correspondence: yangshengmin@sohu.com

Minzu University of China, No.27, Zhongguancun Nandajie, Haidian District, Beijing, China

\begin{abstract}
Ethnology has been introduced into China in the early twentieth century. Its hundred-year evolution can be divided into three phases: ethnology in the "Old China"; ethnology in the "New China", and ethnology in the "New Era" (1978-2008). In the phase of "Old China", relying on introducing the western approaches both in theory and methodology, the Chinese ethnological community offered courses of ethnology and anthropology in dozens of universities. In the 1950s, the early years of "New China", Chinese ethnology became a branch of the Soviet school and made great contributions to ethnic identification, as well as studies on the society and history of ethnic minorities, providing the basis and reference for the "New China" government to formulate ethnic policies. During the "New Period", after 30 years of isolation from the outside world, Chinese ethnology entered again into Western academia and became a member of the international ethnological society. Now, Chinese ethnology has been constructed as an open academic domain and lifted out of the stereotype based on a certain school or ideology. Moreover, it has established its own school with localized characteristic, that is, a historically functional school directed by Marxism.

Before the "New Period", ethnology was revoked due to its characteristic as a "bourgeois" and "revisionist" discipline, but Chinese ethnology has embarked on a most fruitful period of rapid growth since 1978. The past three decades also can be divided into three periods: a decade of restoration and reconstruction in the 1980s, a decade of early development and expansion of research scope in the 1990s, and the decade of golden development after the year 2000.
\end{abstract}

Keywords: Ethnology, Anthropology, Reconstruction

Chinese ethnology started an age of rebirth and rapid development as China entered a new era of reform and opening up in 1978, marked by the convening of the $3^{\text {rd }}$ Plenary Session of the $11^{\text {th }}$ Central Committee of the Communist Party of China (CPC).

Prior to this, ethnological studies were conducted in the name of research on "ethnic minority issues". In fact, as a discipline, ethnology had been revoked in Mainland China for many years and there had been no teaching and research institutions, majors, publications or even columns dedicated to ethnology. In terms of ethnology, unlike traditional disciplines such as history, philosophy and literature, the new era did not only mean the blossoming, but also the regeneration of a lost discipline. In order to help readers understand the features and roles of this hundred-year-long discipline

(c) The Author(s). 2017 Open Access This article is distributed under the terms of the Creative Commons Attribution 4.0 International License (http://creativecommons.org/licenses/by/4.0/), which permits unrestricted use, distribution, and reproduction in any medium, provided you give appropriate credit to the original author(s) and the source, provide a link to the Creative Commons license, and indicate if changes were made. 
in the last three decades, I would like to review its centurial history and briefly summarize its characteristics in the new era.

Ethnology, also referred as "cultural anthropology", emerged in the West as an independent discipline in the mid-nineteenth century. It was introduced in China more than a century ago with the advent of the Chinese version of Evolution and Ethics by T. H. Huxley (translated by Yan Fu) in 1895, and the publication of the Chinese version of Ethnology in $1903 .{ }^{1}$ It has also been over a hundred years since the inclusion of ethnology as an official curriculum in Chinese higher education. ${ }^{2}$

Chinese ethnology is generally considered to have undergone three phases: "Old China", "New China" and "New Period", each of which can be further divided.

\section{Ethnology in old China}

\section{Introduction and rudiment period}

Ethnology and anthropology were initially imported in China during the period from the late nineteenth century to about 1920 , which was also their flourishing period.

The introduction of ethnology is directly related to the political situation of the country at that time. In modern times, the Qing Empire was repeatedly undermined in the encounter with the Western civilization. Having been facing the threat of subjugation and possible annihilation, the Chinese people tasted the pain of isolation from external contact and felt it necessary to learn from the West, ranging from manufacturing technologies to laws and social sciences. To save the nation from doom and strive for survival, many people of insight began to seek a Western approach to transform the country. Zhang Zhidong, leader of the Westernization Movement, stated that "Chinese approaches address physical and psychological issues while Western approaches deal with practice" (Zhang, 1898). Kang Youwei, a leader of the Reform Movement, further held "pursuing a self-strengthening approach by drawing lessons from the result that a strong country always defeats a weak one", and advocated the large-scale translation of Western books. He insisted that "it is better to translate Western books into Chinese, so that the masses can understand Western approaches and build themselves into talents serving for the nation." (Kang, 1987). He also personally opened a school based in Guangzhou, where he taught Western "group studies" (sociology).

After the victory of the 1911 Revolution, a democratic republic was built, which was not only the choice of the Chinese people for salvation, but also the result of the Chinese bourgeoisie politically learning from the West. The new regime had an urgency to build a new social order, a modern code of conduct and new social, national, and ethnic concepts. Both the government and society expected a new system, culture and discourse to replace thousands-year-old and backward feudal institutions, ideas and cultures. In this context, the study of Western cultures, systems and social sciences became an urgent task in shaping a new society. Obviously, Western ethnological theory could provide important implications on how to understand and build a united multi-ethnic country. Hence, Western ethnology was actively introduced into China, driven by the urgent demand of the ruling class and the whole society for Western scientific knowledge.

Against this background, a small number of Chinese scholars, who had initially known or studied ethnology abroad but were not really engaged in ethnological studies, 
actively translated Western writings and published a series of articles, introducing the discipline to domestic academia and the general public. As the name, definition and interpretation of the discipline were translated from the writings and texts of foreign countries, such as the US, the UK, France, Germany, and even Japan, the Chinese versions were often different and not sufficiently accurate, informative or comprehensive, and in some cases, they contained one-sided or even wrong explanations. First and foremost, the Chinese translators who studied in a certain country or were proficient in a certain language often adopted one of the different connotations and definitions of ethnology in the West, especially in the US, the UK and continental Europe. Secondly, the Chinese translators did not have profound understanding of this discipline due to short contact and inadequate research experiences. Thirdly, the Chinese versions were also inaccurate and hardly unified. For example, the Chinese counterparts of ethnology at the time included renzhongxue, minzhongxue and minzuxue. This is similar to the situation in other colonial and third world countries, where the same discipline imported from the West was defined or named in different ways.

In this early stage, many important Western theoretical works in ethnology and anthropology were translated and published in Chinese. Particularly worth mentioning are Marxist or historical materialist ethnographic works, including Friedrich Engels' Origin of the Family, Private Property and the State and The Role of Labor in the Transformation from Ape to Man, and Lewis Henry Morgan's Ancient Society, all published in the 1920s. After years of efforts, the social and academic value of ethnology was gradually recognized and accepted by Chinese academia and government, and the conditions for its establishment as a discipline in China had matured.

\section{Inception}

From the 1920s to the outbreak of the 1937 Anti-Japanese War, ethnological teaching and research entities were founded and Chinese scholars began to study ethnology independently. The department or specialty of Ethnology and Anthropology was established in many universities during this period, such as the Ethnology Team of the Academia Sinica headed by Cai Yuanpei and the Nanjing-based Chinese Society of Ethnology, created in 1928 and 1934 respectively. It meant that ethnology had been incorporated as an independent discipline in the Chinese academia.

From the 1920s onwards, a number of state-owned universities, such as Peking University (PKU), Central University and Sun Yat-Sen University, opened up ethnology-related specialties. Christian universities with more links with the West and private universities also set up ethnological and sociological specialties, such as Yenching University, Tsinghua University, Nanking University, Huaxi University, Lingnan University, Fu Jen Catholic University and Sino-French University. At that time, ethnological and anthropological courses were mainly integrated in the department of sociology and offered by scholars returning to China after overseas study, such as Cai Yuanpei from Germany, Ling Chunshen and Yang Chengzhi from France, Li Ji, Wu Zelin and Wu Wenzao from the US. It was these doctors in sociology and ethnology who had studied abroad during the 1910s-1920s who founded the department of ethnology, sociology or anthropology at their respective universities. 
In addition, institutions specializing in ethnological research or postgraduate training also sprang up. For example, in 1927, the Institute of History and Language was set up in Sun Yat-sen University by Fu Sinian and Gu Jiegang, targeted at graduate students in anthropology, culture and folklore. The mission of the institute was to foster new systematic knowledge based on understanding folklore through field collection of materials, as it was clearly put in the foreword of its weekly publication. In 1928, the Academia Sinica, the highest-level national scientific institution, was founded by the Nationalist Government, and its President Cai Yuanpei created and led the Ethnology Team under the Institute of Social Sciences. Later, the Ethnology Team was again integrated into the Institute of History and Language.

An important fact that symbolizes the emergence of ethnology as an independent discipline is the ethnological field investigation (fieldwork) conducted from the 1920s onward. Fieldwork is the primary way to collect research materials and follows a set of discipline-recognized norms that form the most important feature of disciplinary methodology. The fieldwork carried out by the Institute of History and Language of Sun Yat-sen University in 1928 opened the prelude to independent, standardized ethnological investigation in China. In the summer of 1928, Yang Chengzhi and other scholars travelled hundreds of kilometers to the mountainous areas at the junction of Sichuan and Yunnan in order to study the Yunnan ethnic minorities. The 18-month investigation focused on social organizations, lifestyles, customs, ideologies, languages and writings of the $\mathrm{Yi}$ and Miao ethnicities in more than 200 villages.

In the same summer, the Institute of Social Sciences of Academia Sinica dispatched Yan Fuli and Shang Chengzu to Lingyun, Guangxi, for a six-month investigation to the Yao and Miao ethnicities. In August of the same year, Li Guangming from the Institute of History and Language headed to Songpan and Wenchuan in northern Sichuan for an ethnological survey on the Qiang and $\mathrm{Tu}$, which lasted about 10 months.

The year 1928 marked the beginning of fieldwork made by Chinese ethnologists. Ever since, the field investigation scaled up. Well-known investigations with lasting influence during this period also include a study on the Hezhe ethnicity in the Songhua River by Ling Chunshen in 1929 (The Hezhe Ethnicity in the Downstream Songhua River); dozens of counties in eastern Zhejiang by He Liankui in 1932 (Totem Worship of the She People); visual anthropological investigation to the Miao in western Hunan by Ling Chunshen and Rui Yifu in 1933; the ethnic culture and physical characteristics of the Lahu, Wa and Dai in western Yunnan by Ling Chunshen and Tao Yunkui in 1934 (Investigation Record of Western Yunnan Border); the Tibetan and Qiang by Zhuang Xueben et al. from West China Union University, and the Yi and Qiang in western Sichuan by Ma Changshou et al. from Central Museum (survey reports published); the Yao in Guangxi and Guangdong by Fei Xiaotong and Yang Chengzhi from Yenching University and Sun Yat-sen University respectively in 1935; the Li in Hainan by Shi Tubo, Wu Ruilin and Yang Chengzhi from Lingnan University and the Academia Sinica in 1934 (documentary films). In addition to ethnic minority studies, in-depth investigation and research were carried out on the Han group. The most noticeable works are the investigation to Qinghe Township by Xu Shilian, Wu Wenzao et al. from Yenching University in 1930, the seven-year investigation to Dingxian County, Hebei, presided by Li Jinghan. Also in the 1930s, investigations were conducted respectively by Fei Xiaotong in Kaixiangong Village in Jiangsu, Lin Yaohua in his hometown of Fujian, 
Yang Maochun in Taitou Village in Shandong. Their reports Peasant Life in China, Golden Wings and One Chinese Village: Taitou in Shandong, based on these surveys, are considered classic works of international ethnology, encouraging ethnologists at home and abroad to conduct follow-up investigation and research in these places. In addition, groundbreaking studies on the Han branches were also conducted, such as the Dan people in Guangdong by Lingnan University and the Hakka people by Sun Yat-sen University and Academia Sinica.

Remarkable progress had also been achieved in discipline construction during this period. The normative construction of research methodology and the absorptive application of theory became more mature. This was mainly embodied in continued intensive efforts of first generation scholars to translate and teach Western theory and knowledge in ethnology. At that time, many of the scholars had been directly under the tutelage of ethnological and anthropological maestros. For example, Cai Yuanpei's mentor was the first German ethnology professor when he was studying at the University of Leipzig; Pan Guangdan was mentored by the founder of the historical school Franz Boas in Columbia University, and greatly affected by the renowned master of the evolutionary school Lewis Henry Morgan; the Department of Anthropology of Columbia University where Wu Wenzao studied gathered almost the most famous elites in the US anthropological and sociological community, such as internationally reputed anthropology professors Franz Boas, Ruth Fulton Benedict and Margaret Mead; Yang Chengzhi obtained a PhD in ethnology at the University of Paris, France, and accepted the theoretical approach of the Functional School.

Cai Yuanpei, Pan Guangdan, Wu Wenzao, and Yang Chengzhi completely mastered state-of-art theory and methodology of Western ethnology, anthropology and sociology. Wu Wenzao also won an award for the most outstanding foreign student in nearly a decade for his PhD dissertation at Columbia University. After returning to their home country, they made active efforts by preparing papers, translating works and providing lectures, to systematically introduce the theories of different schools of ethnology, including evolutionary, diffusionist, historical, functional and annales schools, such as Wu Wenzao's introduction and popularization of the British functional school, Yang Kun's analysis of the French annales school and Dai Yixuan's introduction to the American historical school. Thanks to this, the main schools in the international ethnology were disseminated and applied in China. At the same time, well-known Western scholars were hired to give lectures in China and students were sent abroad for study, such as Fei Xiaotong and Lin Yaohua sent by Wu Wenzao to the UK and the US. It is worth noting that some Marxist ethnological works were also partially translated and disseminated. In short, the fledgling Chinese ethnology community comprehensively grasped Western theories and methodologies during this period. The original English textbooks and writings were often used in ethnological and sociological courses in universities, and Chinese scholars often wrote or translated their works into English and published them in foreign journals. Despite the problem of localizing Western words, Chinese scholars did maintain close contact and interaction with the mainstream of international academia. For example, once Bronislaw Malinowski had just completed and not yet published his masterpiece Culture in 1936, Wu Wenzao borrowed the manuscript and asked Fei Xiaotong to translate it into Chinese for publication in China. Hence, Chinese 
ethnology had been built into an independent and full-fledged discipline with the establishment of research entities, implementation of independent research and teaching activities, and the complete mastery of leading theories.

\section{Early prosperity}

From 1937 to 1949, Chinese ethnology entered its early prosperity period, characterized by rapid development and a boom of practical applications. By applying Western ethnology to the in-depth investigation and research of Chinese society, it achieved innovations and development in both theory and methodology. With its own features and style, the Chinese school rose as a striking new force in the field of international ethnology..

\section{Westward shift of focus}

China faced a border crisis as Japan advocated the independence of Manchuria and Mongolia following the outbreak of the War of Resistance against Japanese Aggression (hereafter the Resistance War). Enhancing the study of ethnic minorities and border areas became necessary for resistance and national salvation. With a large-scale move of the majority of institutions of higher education from the east to the west and border areas, the government began to pay more attention to border issues, which gave rise to border politics. Ethnologists and anthropologists also shifted their research focus to the western frontiers and ethnic minority areas. Anthropology was no longer defined as the study of exotic "barbarians" in the West, but as the study of ethnic minorities of border areas in China (Ma, 1947). Wu Wenzao pointed out in the Introduction to Border Politics that the term border contains "political border" and "cultural border", and the goal of ethnology is to promote border culture development and borderland-mainland cultural integration through the study of cultural borders (Wu, 1942).Since then, Chinese ethnology had been more involved in the research on border and ethnic minority issues. Such research direction was formed and continued as a tradition in Chinese ethnology.

The westward shift in focus opened up new fields for the study of ethnic minorities in the western region and contributed to the consolidation of border areas and development of ethnic minority areas. After moving from Shanghai to Guizhou, the Great China University launched an investigation on Miao and Yao ethnicities led by $\mathrm{Wu}$ Zelin. After moving from Nanjing to Sichuan, Nanking University, together with Huaxi University, investigated the Tibetan, Qiang, Yi, Yao, Naxi and Buyi minorities in Sichuan, with Wenyou appointed as leader of this project. Yang Chengzhi and Huang Wenshan from Sun Yat-Sen University surveyed the Miao, Yao and $\mathrm{Li}$ in the Guangdong and Guangxi regions. Chen Xujing and Jiang Yingliang from Yangling University and Zhuhai University conducted investigation on the Miao, Yao, Li, Dai and Gaoshan. Tao Yunkui led a survey by Nankai University on the Yi, Naxi and Dai. Sun Wenben and Ma Changshou presided over the survey by Central University on the ethnic groups in Xinjiang and southwest areas. At that time, a large number of scholars gathering in Yunnan conducted an in-depth study of ethnic groups on site and produced famous works that are still regarded as ethnological classics, such as Fei Xiaotong's Farmland in Lu Minzu University of China Village, Fang Guoyu's Kava Mountain Investigation and Xu Langguang's Under the Ancestral Shadow. 
Ethnological journals greatly increased owing to the attention from all walks of life during this period, in contrast to the suspension of many periodicals due to financial difficulties and other reasons. There were over 30 newly-founded publications relating to ethnology and border culture, such as Collection of Anthropological Papers (published in 1938), Collection of Ethnological Studies (founded in 1936), Southwest Frontier Monthly (founded in 1938) and Public Opinions on Border Governance (founded in 1941), as well as The Land and the People, Frontier Culture, Anthropological Series, Frontier Humanities, Mongolian and Tibetan Affairs Monthly, Northwest Discussion, Sociological Community, Frontier Newsletter (Chen and Wang, 1981), which were all founded during the Resistance War.

\section{Formation of localized features}

Chinese ethnology built its own localized style on a completely imported discipline through in-depth research on Chinese society that also met social expectations. The formation of localized features marked the gradual maturity of Chinese ethnology and drew widespread attention and comments by international ethnologists. These features are summarized as follows:

(1) Emphasis on application. Compared with their Western counterparts, Chinese ethnologists paid more attention to the application of ethnology to solve practical social problems. While the fulfillment of their social responsibility has always been part of the tradition of Chinese intellectuals, China's internal and external problems, especially in the past century, forced the scholars to face up to the reality. The inception of ethnology met the need of building a new country and society at the end of Qing Dynasty and the beginning of the Republic of China, and aimed at salvaging the nation, as well as protecting and building the frontier after the outbreak of the Resistance War. Scholars considered the discipline a useful tool to serve the community rather than merely academic research. As put by Wu Wenzao, "approaches of knowledge need to be classified in theory, but they are closely connected in practice." (Wu, 1942). Fei Xiaotong also noted that "the study of the society and history of different ethnicities is intended to boost development, and in this process, the comparison between the sociological knowledge and the general law of social development is used as a tool for our concrete analysis. In other words, theory is combined with reality. The study is more than theoretical comprehension and output, but also serves for practical purposes, i.e. laying a scientific, factual basis for the social reform of ethnic minorities and providing opinions in the interest of the same ethnic minorities." (Fei, 1985).

The vision of ethnology as a kind of tool and the fact that its application outweighed disciplinary demarcation was due to the absence of strict boundaries among ethnology, sociology and anthropology in China. Both in universities and research units, the discipline usually encompassed courses of the three specialties. For this reason, the older generation of Chinese sociologists was mostly composed by ethnologists and anthropologists, a trend that lasted until the mid-twentieth century.

(2) Both Northern and Southern factions attached importance to history. Based on their theoretical schools, research methodology and focus, Chinese ethnologists can be roughly divided into the Northern and Southern factions. The Southern Faction was dominated by scholars from Eastern and Southern China, and was represented 
by Academia Sinica and Yang Chengzhi from Sun Yat-Sen University. Under the impact of the American historical school, the Southern Faction scholars gave importance to ancient literature and archaeological materials, focusing on the cultures of different ethnic groups. Their research, typically conducted from an evolutionary perspective, put more emphasis on detailed description, comprehensive investigation and data accumulation. With Yenching University as the core institution and Wu Wenzao as the representative, the Northern Faction mainly relied on the European functional school and stressed the study of the Han community. In addition to the interpretation of theories, emphasis was also laid on the investigative analysis of the relations among various social phenomena and historical literature. Historical literature was valued by both factions, which is one of the most important features of Chinese ethnology, but it was used in different ways. The Southern Faction cast more attention to ethnographic data, directly carrying out research on ethnic history, such as the origin of ethnic groups and the historical relations between them. It directly classified the research on ethnic history into ethnology and presented a lot of achievements in this regard.

The Northern Faction had different approaches towards the use of historical literature, insisting on the differences between themselves and historians. Wu Wenzao made it clear that historical literature was used mainly "in a go-upstream method, i.e. an approach that looks back upon the past", and "the history we want to know should still play a role institutionally" (Wu, 1942), i.e. history that still impacts the reality. In other words, the review of historical literature in ethnology, anthropology and sociology serves to illustrate the nature of contemporary social phenomena and affairs rather than to clearly narrate the historical process itself. In this way contemporary society can be explained deeply and clearly.

In light of the voluminous historical literature and profound historical tradition of a complex society like China, it is obviously inappropriate to directly apply Western approaches for studying the simple society of colonies. Despite differences in the methods and perspectives of using historical literature, the emphasis on historical examination is common in both the Northern and Southern factions and unique to Chinese ethnology. Famous American anthropologists Maurice Freedman and David Schneider discussed the achievements of Chinese scholars in this regard, noting that considering its long history and complex population, the study of Chinese society requires more macroscopic approaches of observation and analysis, and the historical approach is exactly applicable (G. William Skinner, ed, 1979)

(3) Localized ethnology and community studies. In the West, ethnology is traditionally the study of colonies, especially ethnic groups and societies without written history, referred to as "primitive society" by Western scholars. However, China is a multiethnic country without colonies, and is divided into inland areas, border and ethnic minority areas instead of suzerain and colonies. "Anthropology is applicable to colonial administration in the West, but in China, it serves for governance, education, welfare and cultural change study in the border areas", said Wu Wenzao (Wu, 1942).The ethnological research in China then evolved into a local ethnology different from that in the West. It drew the attention of international academia because of the many changes brought to traditional ethnology, covering research field, methodology and theoretical interpretation. 
Western ethnology and sociology were clearly divided in research field and methodology. The former examined and studied other ethnicities, "primitive societies", rural societies, and societies without written languages, while the latter focused on native societies, "civilized societies", and urban societies. Based on the theoretical analysis of the functional school, Wu Wenzao studied local Chinese society by combining the approach of ecology study in sociology, i.e. to examine the relationship among population, geography and social organization, with the approach of objective observation and empirical study of other ethnicities and villages in ethnology. This local research was referred to as "community studies", which has exerted a significant impact on the international academia. When it comes to methodology, Wu Wenzao noted that "in the author's view, anthropology and sociology are really unified, especially in China." (Ibid). Localized ethnology based on community studies has left a number of influential works in international anthropology, ethnology and sociology, such as Fei Xiaotong's Peasant Life in China, Lin Yaohua's Golden Wings, Li Jinghan's Dingxian County and Xu Guiguang's Under the Ancestral Shadow. "I dare to predict that Dr. Fei's Peasant Life in China will be a milestone in anthropological fieldwork and theoretical work", Malinowski ever stated in the preface (Fei, 1986).Even today, some Western scholars believe China's "community studies" to be a very important chapter in anthropological history (Maurice Freedman, 1962). Although their methodology may be inspired by American rural sociology, Chinese ethnology and anthropology mainly focused on local research, in contrast to the overseas research of their US counterpart. A Chinese school in ethnology came to the fore as a discipline that relied entirely on Western theory and methodology, and then became more independent. It is believed that Chinese ethnology and anthropology during this period reached an insurmountable peak (Hu, 2006; Xin, 2004).

\section{Marxism and Chinese ethnology}

International ethnology and sociology saw the emergence of social analysis and research based on the Marxist theory. However, due to the political orientation of several governments, Marxism is held in contempt to a certain degree in Western societies, and especially the Marxist theory of class is rarely accepted in the study of society and political economics, which undermines its dissemination in Western. Therefore, the international ethnological community, which is dominated by Western scholars, has always seen the free development and dominance of other schools. In ethnology and anthropology, theories used to explain society must be based on empirical evidence. Regardless of what school they belong to, all theories basically rest on social investigations and reflect more or less the real side of social phenomena at the macro or micro level. Some Western ethnologists came to conclusions that are consistent with Marxism, although they did not directly quote Marx, such as Morgan's study of native Americans. Engels noted in the preface to Origin of the Family, Private Property and the State that "Morgan in his own way had discovered afresh in America the materialistic conception of history discovered by Marx forty years ago, and in his comparison of barbarism and civilization it had led him, in the main points, to the same conclusions as Marx." (Engels, 1972).Morgan is not alone in this regard in the Western ethnological academia. There were also instances of social analysis against Marxist theory from a certain point of view. For example, The History of Human Marriage authored by 
Edvard Westermarck disagreed with the Marxist theory of marriage and family evolution process in the development of human society, but has been recognized by the majority of Western scholars.

However, Marxism is after all the most influential doctrine in the twentieth century, exerting an impact to different degrees on various fields of the social sciences, both in China and in the West.

The impact of Marxism on Chinese ethnology can be dated back to years before the establishment of the New China in 1949. At that time, the majority of Chinese scholars actually accepted the theories of historical materialism and evolution, but the Marxist theories of class and political economics were hardly recognized, which of course was directly related to the anti-Communist, pro-Western policies of the Kuomintang Government and the isolation of Marxism by the whole society, including academia. In the liberated areas, especially in Yan'an, however, preliminary research on ethnic issues was conducted under the CPC's leadership, delivering such representative outcomes as Issues Concerning the Hui Ethnicity and Issues Concerning the Mongolian Ethnicity. There were also works on historical and cultural development that used Marxist theories to interpret and analyze China's ethnic problems and histories, such as Fan Wenlan's A Compendium of General History of China and Hou Wailu's History of Chinese Ancient Society. The preliminary Marxist research and analysis of China's ethnic issues, society and history laid a certain foundation for the popularization of Marxism in Chinese academia of ethnology and other social sciences after 1949.

\section{Moving back to the east and stagnation}

In the years after the end of the Resistance War in 1945, Chinese universities moved from the Western and Central China back to the large cities of the South-East. With the mitigation of the border crisis, the research on border governance and ethnic issues experienced a decline, with some scholars giving up altogether academic research for the reconstruction in the East. University enrollment in ethnology and anthropology also became difficult amid the turbulence caused by the Civil War. As a combined result of these factors, Chinese ethnology fell into stagnation during this period.

In the years following 1945, academics in the fields of ethnology, anthropology and sociology, like other intellectuals, were required to make a personal choice between the two parties during the Civil War. The majority of academic leaders stood in opposition to the Kuomintang dictatorship and in pursuit of democracy. Among them, Fei Xiaotong was intimidated by the authorities and forced to hide in the US embassy. In the eve of the liberation of the country, he declared in a meeting in front of hundreds of people, "let us await dawn in the dark. The dawn is not far distant." In December 1948, he met Chairman Mao Zedong in the then CPC headquarters in Shijiazhuang. Wu Wenzao, who was the minister and head of the Chinese diplomatic delegation in Japan, returned to China shortly after the liberation of the country while rejecting the invitation of Yale University. Many well-known ethnologists played an active role in the liberation of ethnic minority areas. For example, Li Anzhai and Ren Naiqiang provided valuable first-hand information that helped the People's Liberation Army (PLA) to understand the Tibetan situation and design the route to Tibet in 1950. As advisers to the $18^{\text {th }}$ Corps, they accompanied PLA to Tibet and provided assistance in running schools and offering training courses about Tibetan culture. They were therefore highly praised by Marshal He Long. Professor Gu Bao from Lanzhou University had devoted 
to ethnic studies since the entry to Xinjiang together with PLA in October 1949. Lin Yaohua, Song Shuhua and Wang Xiaoyi were also involved in the entry into and liberation of Tibet. Yang Chengzhi led the working group of the Central Commission of Ethnic Affairs to prepare a pile of materials supporting central committee decisions.

\section{Ethnology in the new China}

From 1949 to 1964, Chinese ethnologists experienced two severe large-scale tests: extensive self-transformation and full participation in the national ethnic survey which resulted in outstanding achievements. The self-transformation consisted in the comprehensive critique of "Western bourgeois ethnology" and the full acceptance of the Soviet model and ideology. This is also known as the "renewal" of Chinese ethnology through socialist transformation. During this period, Chinese ethnology entered its golden age, with the accumulation of massive ethnographic data while serving as the backbone in an unprecedented government-sponsored ethnic identification and social and historical investigation of ethnic minorities.

\section{Renewal: acceptance of the soviet model}

Adjustment of faculties and the research department

After the liberation of the country, China fully fell into the Soviet-led socialist camp in political, military, economic and cultural dimensions, and higher education was no exception. In the Soviet Union, sociology was revoked in the 1930s because of its bourgeois characteristic; with regard to anthropology, the cultural branch was also revoked and the physical branch left in the field of human evolution research as part of biology. As one of the inevitable results of comprehensively learning from the Soviet Union, New China also revoked sociology and anthropology on the grounds of that they were Western "bourgeois disciplines". Physical anthropology was integrated into the Institute of Paleontology and Paleoanthropology of the Chinese Academy of Sciences (CAS), completely detaching from social sciences. Ethnology was luckily preserved as a part of historical studies according to the Soviet classification of disciplines, but with the 1952 National Adjustment of Departments, all the departments of ethnology were removed from universities, the teaching staff reduced, and undergraduate enrollment canceled.

Before the liberation, the specialty of ethnology existed in the departments of sociology or anthropology. As there were no clear boundaries among these similar disciplines in China, Chinese anthropologists and sociologists were mostly deemed as ethnologists. For example, Fei Xiaotong's Peasant Life in China and Lin Yaohua's Golden Wings are recognized as works in sociology, ethnology and anthropology. Because of fuzzy disciplinary boundaries, some sociologists were sent into other fields after the adjustment of faculties. For example, with the removal of their departments, Pan Guangdan and Wu Wenzao, who were originally Deans of the Department of Sociology in Tsinghua University and Yenching University respectively, and Wu Zelin and Yang Chengzhi, originally Deans of the Department of Anthropology in Tsinghua University and Sun Yat-Sen University respectively, were transferred to the Minzu University of China Minzu University of China.

In 1952, the departments of sociology, anthropology and ethnology were withdrawn in a large-scale adjustment of national colleges and universities. Leading scholars in 
Yenching University, Tsinghua University, Sun Yat-Sen University, Fu Jen Catholic University and Peking Institute were mostly transferred to the Research Department of MINZU UNIVERSITY OF CHINA MINZU UNIVERSITY OF CHINA. As a result, this department became the last stronghold of ethnology and sociology and the earliest ethnological teaching and research center of New China. It encompassed a group of famous scholars, including Weng Dujian, Pan Guangdan, Wu Wenzao, Wen You, Yang Chengzhi, Fei Xiaotong, Lin Yaohua, Jian Bozan, Wu Zelin, Feng Jiasheng, Wang Zhonghan, Cheng Suluo, Shi Lianzhu, Chen Yongling, Wu Heng, Wang Furen, and Song Shuhua.

This rising group of top-class ethnologists, sociologists, anthropologists and historians, originally headed by Professor Weng Dujian, absorbed the faculty and students of the Department of Ethnology of Yenching University. Under this umbrella, there were research offices in the Northwest (led by Feng Jiasheng), Northeast Inner Mongolia (led by Wengdu Jian), Southwest (led by Jian Bozan), Tibet (led by Lin Yaohua), Southeast (led by Pan Guangdan) as well as a book archive (directed by Wang Ming Yu), and later, an office of ethnic minority research (led by Wu Wenzao) and the former office on national heritage research (led by Yang Chengzhi). Fei Xiaotong served concurrently as Vice President of Minzu University of China Minzu University of China.

The specialty of ethnology was kept only in Minzu University of China Minzu University of China as the case of Soviet colleges and universities (in the Department of History). A small number of graduate students were recruited for conducting research on ethnic minorities when courses were available for the cultivation of associate doctors in ethnology. Founded in 1956, the Department of History did not recruit undergraduate students in ethnology though offering courses of ethnography by its Ethnological teaching and research section.

\section{Critique of "bourgeois ethnology"}

The founding of New China represented more than a simple regime change, also symbolizing a complete break with Old China. It required the construction of new social systems, ideas and concepts. Higher education was also bound to renew itself. New systems and ideas could be drawn from the Soviet Union, but before that, old concepts and ideas had to be abandoned. With respect to ethnology, the thorough critique of Western ethnology covered not only the entire theoretical framework, which was imported from the West, but also the ideas and concepts of old-style Westerneducated teachers.

Starting in September 1951, a nationwide ideological reform of teachers was carried out for four to six consecutive months. The movement was centered on ideological education through the study of the basic theories of Marxism-Leninism, and encompassed learning the CPC's guiding principles for a new democratic revolution, as well as Marxist philosophy, political economics and social development history, and understanding and discussing domestic and international events. The textbooks consisted of selected readings from the works of Marx, Engels, Lenin and Mao Zedong. Ethnological instructors were also required to study Engels' Origin of the Family, Private Property and the State and The Role of Labor in the Transformation from Ape to Man, Morgan's Ancient Society, and Stalin's Marxism and the National Question and Marxism and Problems of Linguistics. The movement was a process of listening to reports, learning documents and materials, conducting criticism and self-criticism, and writing personal summaries of thoughts. 
In the process of criticism and self-criticism, most scholars carried out a profound personal introspection of their ethnological teaching and research. First, the Western ethnological theories and methodologies accepted in the past were now considered an enslaving form of education, and the research conducted on this basis was considered to be unconvincing or even wrong. More specifically, it was believed that the major works failed to reflect proletarian views and positions or to integrate class analysis, and relied on empiricism. Representative Western works and basic theories of ethnology and anthropology were negated for being characterized by bourgeois values, colonialism, idealism and racism. Moreover, there was a complete negation of personal research and a thorough critique of teaching activities, which were considered to serve as Western bourgeois propaganda.

After witnessing of the corruption of the old regime, Western hegemony and the oppression of Old China, followed by the prosperity of New China, scholars supported the CPC and socialism, and mostly conducted sincere criticisms and examinations. However, the complete negation of established theories and methodologies and previous studies resulted in self-abasement, and sparked a fervent desire to learn from Soviet ethnology. These scholars expressed the determination to reinvent themselves as soon as possible as red specialists and intellectuals.

\section{Learning from the soviet union}

How could scholars behave as red intellectuals? In what way could "proletarian ethnology" be built to serve the nation after a thorough critique of the Old China "bourgeois ethnology"? The only way was to learn from the Soviet Union and substitute the Western model with the Soviet model. At that time, the Soviet school had risen as a unique school in international ethnology, which came into existence in the late 1920s and formed its own independent features in the late 1930s. The Soviet school advocated the combination of ethnology, anthropology (physical anthropology) and archeology. Its features can be summarized as follows: (1) close connection with the socialist construction of the country under the guidance of dialectical and historical materialism; (2) special attention to the origin of Soviet ethnic groups through a comprehensive study in ethnology, anthropology and archeology;(3) highlight on the study of primitive social history; (4) targeted systematic investigation of the material and spiritual cultures of ethnic groups; (5) emphasis on foreign nations (Yu. Bromley ed, 1974).

The first step in learning from the Soviet Union was to apply the Soviet model in the division of disciplines. The Anglo-American approach divided anthropology into four branches: ethnology (cultural anthropology), linguistics, archeology and physical anthropology. In the Soviet model, ethnology was withdrawn and the other three branches set up as independent disciplines, and the specialty of ethnology was generally integrated into the department of history. Hence, in China, ethnology was classified as a branch of history (this classification in undergraduate education is still recognized by the Ministry of Education, although graduate courses nowadays elevate ethnology as having an equal status to history). Specifically in higher education, it was necessary to translate Soviet materials and related works. In the early 1950s, the Soviet Union provided China with a huge number of teaching materials and professional books. According to statistics, there were 3000 books translated and published in Chinese and 20 million copies of these books were issued during 1949-1955. (Gu, 2000a, b)Thanks to this translation endeavor, carried out in a very short period of time, scholars quickly 
became familiar with Soviet ethnology, for which they expressed great admiration, with someone even publicly wrote that "both before or after the revolution, Russia has presented a theoretical level of this science (ethnology) unmatched by the rest of the world." (Research Department of the Central University for Nationalities, 1955) During this period, as many as 11,000 Chinese students, including those majoring in ethnology, were sent to the Soviet Union. A great many Soviet experts, including ethnologists, offered lectures in China and conducted collaborative studies with Chinese scholars. The most famous of these experts was Professor Cheboksarove, Director of the Department of Ethnology of Moscow State University, who lectured on Soviet ethnology in the MINZU UNIVERSITY OF CHINA Research Department. Graduate students that received the education mostly rose to fame in the Chinese ethnological academia. The viewpoints they held were considered by Western scholars as being part of the Soviet school.

The basic ethnology teaching materials in China were largely translated from Soviet textbooks, such as Introduction to General Ethnology, Development of Soviet Ethnology, Anglo-American Ethnography in the Service of Imperialism, Outline of Primitive Cultural History, Critique of Bourgeois Ethnology, and What is Ethnology. A large number of the writings of Soviet scholars about ethnic history and other nations were also published in Chinese, such as Collection of Ethnic History Translations, African Ethnography and American Ethnography, while recently-published papers and research findings were gathered into the Collection of Translations on Ethnic Issues. Soon the majority of the Chinese ethnological community mastered basic Marxist theories and began their research in accordance with the Soviet model.

Soviet ethnology stressed its will to serve the national construction of the country and the ethnic policies of the Soviet Communist Party, and took the position of safeguarding Marxism-Leninism from Western imperialism. Therefore, its focus was supposed to be political and practical. Affected by this, Chinese ethnology soon showed the same tendency, particularly in the fields of "primitive social history", "economic and cultural types" and "ethnic definition and identification".

Primitive social history was emphasized as "a basis to clarify the basic theory of historical materialism" (Lin, 1984). Lin Yaohua developed the syllabus for Primitive Social History commissioned by the Ministry of Education, and Yang Kun prepared the handouts for Primitive Social History and Ethnography. These syllabus and handouts were greatly affected by Outline of Primitive Cultural History, but mostly cited Chinese cases. The courses were offered in the departments of history, politics, or literature in several universities. The study of economic and cultural classification was based on the theory of Soviet scholars. China Economic and Cultural Types, co-authored by Lin Yaohua and Cheboksarove and published in 1961, integrated the theory put forward by Soviet lecturers with specific cases from China's ethnic minorities. In fact, today this study is defined as ecological ethnology (or ecological anthropology). To our knowledge, this was published even a few years earlier than related studies in Western anthropology and ethnology. In this sense, Soviet ethnology was unique compared with its Western counterpart, in addition to adherence to the basic Marxist theory. Ethnic definition and identification was a research topic of common concern for Soviet and Chinese scholars. At that time, Chinese ethnologists had to come up with supportive standards and technical solutions in theory and methodology as the Chinese government had kicked off the work of ethnic recognition nationwide. 
Through the socialist education and transformation achieved by studying Soviet ethnology and Marxist theory, Chinese scholars took on an entirely new look, particularly in research priorities, theories and methods. In 1956, two leading scholars, Fei Xiaotong and Lin Yaohua, pointed out four research priorities in Chinese ethnology in a co-authored dissertation: (1) identification of ethnic minorities; (2) social nature of ethnic minorities; (3) culture and life of ethnic minorities; and (4) religion of ethnic minorities (Fei and Lin, 1957). These four tasks were confirmed by the Science Planning Commission of the State Council in the Draft Plan for Philosophy and Social Sciences (1956-1967). Apparently, the voices of Fei and his colleagues were heard and obtained the central government's recognition on major issues concerning discipline development.

In a review of Soviet influence on Chinese ethnology, American scholar Gu Dingguo said that Soviet scholars taught their Chinese counterparts to combine ethnology, ethnic history and archeology with socialist construction ( $\mathrm{Gu}, 2000 \mathrm{a}, \mathrm{b})$. The example of the Soviet Union was important due to the fact that Chinese ethnological academia was able to quickly start playing an important role in and make outstanding contributions to the government's ethnic work in the 1950s.

While being completely incorporated into the Soviet school, Chinese ethnology showed repulsion or even hostility towards various Western schools. It became a one-sided discipline with diplomatic inclination to the Soviet bloc, and completely cut contacts and exchanges with its Western counterparts, establishing on the other hand connections with the countries of the socialist bloc, such as East Germany, Bulgaria, Czechoslovakia, North Korea, Romania, Mongolia and Vietnam, which was embodied in the introduction to its research findings in the Collection of Translations on Ethnic Issues.

\section{Winning Glory: Ethnic identification and social and historical surveys}

In the early 1950s, the involvement of ethnologists was necessary to the ethnic work of the new government of this multi-ethnic country, covering ethnic policy development, theory establishment, basic situation survey, and information collection and accumulation. Chinese ethnologists who had initially mastered Marxist and Soviet school theories turned to border and ethnic minority research. Despite the constraints to discipline construction, the scholars involved in national ethnic surveys and research were highly valued by the government and society, and even received the government's support. They provided assistance in the 14-year ethnic identification work and 8-year ethnic minority social and historical survey launched nationwide in 1950, which came to some preliminary conclusions on the social nature of ethnic minorities based on a comprehensive study. Totally over 400 series books on the history and languages of ethnic groups, totaling over 60 million words, were published by provincial and regional investigation teams. The unpublished survey materials were far more, mainly carried out by research institutions and scholars. Ethnic identification and social and historical surveys contributed significantly by paving a solid foundation for ethnic policy development and subsequent ethnic research in the New China.

\section{Participation in ethnic identification and large-scale surveys}

The work of ethnic identification was kicked off in 1950, and a large-scale survey started in 1953, extended to 1964 and completely finished in 1979. More than 400 ethnic groups reported in the country were classified into 56 identified main ethnic 
groups after dozens of years of large-scale surveys and research. This was the first time that China scientifically discerned its ethnic composition. This social and historical nationwide survey began in 1950 and lasted until 1958, after which investigation teams prepared reports and conducted case investigations. The entire work basically came to an end in the 1970s.

The whole ethnological community was involved in these two campaigns. Among them, the MINZU UNIVERSITY OF CHINA Research Department and the Institute of Ethnic Studies of the Chinese Academy of Social Sciences (CASS) played the most important role. Before the start of social and historical surveys on ethnic minorities, experts from the MINZU UNIVERSITY OF CHINA Research Department drafted the Reference Outline of Social Nature Investigation and presided over the training of investigators that introduced basic knowledge and methodology. Since 1953, ethnologists became fully engaged in the survey, and many of them led local investigation teams. Among them, Lin Yaohua, Fu Lehuan, Wang Furen and Chen Xuebai went to Inner Mongolia; Pan Guandan, Wang Mingyu, Hu Kejin and Yang Ziqiao engaged in ethnic identification of the Tuin western Hunan; Lin Yaohua, Shi Lianzhu, Wang Furen, Huang Shupin, Chen Fengxian and Wang Xiaoyi conducted ethnic surveys in Yunnan; and Fei Xiaotong and Song Shuhua investigated the Chuanqing and Chuanlan people in Guizhou.

The guiding and exemplary efforts of ethnologists in ethnic identification were also seen in post-fieldwork comments and influential publications, such as Fei Xiaotong's Issues on Identification of Ethnic minorities, Fu Lehuan's Issues on Identification of Dahuer Ethnic Group, Wang Mingyu's Overview of Tujia Ethnic Group in Xiangxi, Pan Guangdan's Tujia People in Northwestern Hunan and Ancient Ba People, and Historical Source of Salar Ethnic Group and Economic Life of the Tu People in Qinghai by Song Shuhua et al.

\section{Edition and publication of the Collection of Translations on Ethnic Issues and Collected Papers on China Ethnic Studies}

In 1954, the Counselors' Office of the State Ethnic Affairs Commission (SEAC) started compiling the Collection of Translations on Ethnic Issues, as internal information material. In 1955, the MINZU UNIVERSITY OF CHINA Research Department took over the work and published it. In 1958, the publication was renamed Ethnic Studies, and was edited and published by the CASS Institute of Ethnic Studies. In September 1955, the MINZU UNIVERSITY OF CHINA MINZU UNIVERSITY OF CHINA Research Department began to irregularly publish the Collected Papers on China Ethnic Studies, which contained influential papers and survey reports on ethnic research and work in the New China. It was these two publications on ethnology and ethnic theory that spread the preliminary influence of ethnology in the country.

Other research and social work

Since its inception, MINZU UNIVERSITY OF CHINA Research Department emerged as one of the most important research and consulting agencies for developing ethnic policies and handling ethnic affairs. It often received letters from agencies, groups and individuals across the country to inquire about ethnic issues and obtain access to ethnic policies and knowledge, and replied to letters transferred from the SEAC. In addition to social surveys, the department also compiled and published a series of important works, such as the data-rich Compilation of Biographical Records of Ethnic 
Groups, co-authored by Jian Bozan and Wu Heng and published by Zhonghua Book Company, Index to Monographs and Papers on Ethnic Groups on the China-Burma Border, co-authored by Shi Zhongjian, Sun Cheng, Liu Yaohan, Zhou Rucheng, Yang Jiarong and published by the Research Department, Overview of Tibetan Society, coauthored by Lin Yaohua, Li Youyi, Song Shuhua, Wang Furen, and Historical Compendium of the Uyghur Ethnic Group, co-authored by Feng Jiasheng, Cheng Suluo and Mu Guangwen.

In 1956, the Department of History was set up in MINZU UNIVERSITY OF CHINA. It established New China's first specialty of ethnology and recruited graduate students as associate doctoral candidates. The MINZU UNIVERSITY OF CHINA Research Department continued its research work in ethnology. On June 23, 1958, the Institute of Ethnic Studies (predecessor of the current Institute of Ethnology and Anthropology) was officially established under the Department of Philosophy of the Chinese Academy of Sciences, based on the preparation work started in 1957. The main members of the Institute came from the Research Department.

A brief comment The Soviet-style transformation in the 1950s made Chinese ethnology community fully accept Marxist theory in social study and interpretation, a methodology that still exerts an important impact today. However, gains were accompanied by losses. Ethnologists completely lost contact with the outside world, with the exception of the foreign socialist camp, as a result of one-sided foreign policies. They became "deaf and blind", listening to no one other than the Soviet school, and wore colored glasses when commenting on their own history and other schools reviewed by foreign scholars (Maurice Freedman, 1962). This comment no doubt makes sense because Western ethnology was not useless at all as Soviet scholars said and undoubtedly played an inseparably important part. History proved that it is a simplistic approach to consider all Western scholars and works as "bourgeois" without academic evidence, and this is harmful to the development of the discipline.

\section{Ethnic studies in substitution of ethnology}

In 1957, the nationwide "anti-rightist" campaign began. Most of the leading ethnologists were stricken. For example, Pan Guangdan, Wu Wenzao, Chen Da, Yang Chengzhi, Fei Xiaotong and Wu Zelin were judged as rightists and deprived of the right to engage in research and publish works, as their findings were considered as "poisonous weeds" of "bourgeois ethnology". Among the 200 or so scholars engaged in the social and historical survey of ethnic minorities, 22 were classified as rightists and many others publicly criticized for "bourgeois speeches", such as Yang Kun, Li Youyi and $\mathrm{Cen} \mathrm{Wu}$, and their research and publications were silenced. All these people were defined as "bourgeois ethnologists". In June 1958, a meeting on ethnic studies was jointly held by the Ethnic Committee of National People's Congress (NPC), CAS and MINZU UNIVERSITY OF CHINA MINZU UNIVERSITY OF CHINA. With class struggle as the background theme, the meeting depreciated the influence of bourgeois ethnology and sociology on social surveys, announcing the plan to "pull out the white flag of capitalism and plant the red flag of socialism", and criticizing a number of old ethnologists. It adopted the "leap forward plan" for ethnic 
studies, emphasizing the" political leadership and value of the present over the past" in ethnological surveys and studies.

"The national meeting on scientific ethnic work, recently held by the CAS Institute of Ethnic Studies and MINZU UNIVERSITY OF CHINA MINZU UNIVERSITY OF CHINA, summed up the experience of social and historical surveys of ethnic minorities over the last two years and thoroughly criticized reactionary bourgeois views, methods and erroneous tendencies towards bourgeois nationalism," as was noted in a CEAC report to the CPC in 1958.

Prior to 1957, ethnic identification and social and historical surveys followed to a large extent the fieldwork standards under the guidance of ethnologists. After 1957, however, most of these norms were criticized for having bourgeois characteristics and the ethnic work was changed into a movement of the masses like the "Great Leap Forward". Not only did social and historical surveys suffer losses, but the popularity and prestige of ethnology were also damaged.

After 1958, there was an escalation in the criticism of well-known ethnologists or the so-called "bourgeois scholars" and Western traditional ethnological theories. Despite continued ethnic studies, ethnology was further weakened as a discipline with the stagnation of theoretic and methodological research. The Soviet characteristics in its research model, framework and priorities were maintained till the discipline reconstruction in 1978.

"The principal contradiction in the current society is between the proletariat and the bourgeoisie. In the field of ethnic studies, the principal contradiction is between the proletarian ideology and reactionary bourgeois ethnology. As the bourgeois ethnology serves for imperialism, bourgeois ethnologists in Old China were actually cultural compradors providing intelligence for imperialism. The Chinese people have always been negative about bourgeois ethnology in principle and of course, shall not tolerate the poison after the liberation of the country. Practice is the only fundamental source of scientific knowledge in ethnology," as it was written by a major MINZU UNIVERSITY OF CHINA MINZU UNIVERSITY OF CHINA leader after the "antirightist" campaign in 1958. When Fei Xiaotong and other scholars explained why they adopted the methodology of Western ethnology, this leader said "the functional school uses functional analysis instead of Marxist-Leninist class analysis to achieve the purpose of service of imperialism. They believe the methodology of bourgeois ethnology is useful except for its reactionary characteristic. We believe that bourgeois ethnology is downright reactionary pseudo-science that should be resolutely opposed no matter what attempt to revive it." He added in the end, "Soviet ethnology is a valuable reference for us." (Su, 1958).

In this tense atmosphere, scholars free from criticism were also involved in the antirightist campaign, ushering in another round of criticism of Western theory in ethnology. For example, famous scholars carried out comprehensive critique of various Western schools of ethnology, anthropology and sociology, and referred to the theories they had learnt in the West as "bourgeois school for the service of imperialism" and "reactionary theories for the service of bourgeois" (Liang, 1964). Inside the academia, there was criticism of the rightists and so-called "bourgeois scholars". Fei Xiaotong was called "a lackey of imperialism" and "traitor of the peasant class" for his book entitled Peasant Life in China (Maurice Freedman, 1962). 
At this time, all Western theories and methodologies in ethnology were known as "reactionary pseudo-science". The development of ethnology was not primarily reliant on the strength of these scholars. "The fundamental forces of ethnic studies are party organizations and party-led agencies and people engaged in ethnic work," according to the aforementioned MINZU UNIVERSITY OF CHINA MINZU UNIVERSITY OF CHINA leader (Su, 1958).

In 1958, Sino-Soviet relations began to deteriorate. The next year, with the Soviet Union's unilateral abrogation of hundreds of assistance and cooperation agreements, all Soviet experts including ethnologists were withdrawn from China, and bilateral academic exchanges, including the ethnological aspect, came to an end. The plans for the joint compilation of an East Asian and Soviet publication to commemorate Chinese ethnology were also canceled. The Sino-Soviet split became fully open in Chinese society with the CPC's open letter titled Nine Commentaries on SCP Central Committee. The originally exemplary Soviet ethnology was immediately criticized as "revisionist ethnology", which implicated the scholars engaged in Soviet ethnological research. The adjacent criticism of rightists, bourgeois ethnology and revisionist ethnology actually left Chinese ethnology homeless. It was suggested that Marxist ethnology did not exist and ethnology in itself was a bourgeois discipline (Song et al., 2004).

In 1958, the Institute of Ethnic Studies was formally set up under CAS, rather than the planned Institute of Ethnology. In the 1960s, "ethnic studies" completely replaced ethnology.

After 1963, the academic criticism of modern revisionism and bourgeois views was magnified as the whole country gave priority to "class struggle", disqualifying ethnology from the status of discipline. There were articles by famous old ethnologists criticizing "bourgeois and revisionist ethnology" (Wang et al., 1998). The most representative was an article by Shi Jin in 1964, which questioned whether ethnology was science. "In nominal terms, there are a variety of ethnologies, such as Western ethnology, Soviet ethnology and old Chinese ethnology; practically speaking, they are all bourgeois ethnology. The bourgeois ethnology is not science at all, and neither are bourgeois social sciences. Socialist China only needs to criticize instead of carrying forward bourgeois social sciences ... there should be no room for the continued existence of old Chinese ethnology in socialist new China. For us, the only ethnology should be based on Marxism-Leninism and Mao Zedong Thought. It is the most fundamental and complete science for studying all ethnic issues. Therefore, we believe it unnecessary to develop Marxist ethnology other than the above-mentioned one. If there is such ethnology, it is nothing more than bourgeois ethnology labeled Marxism-Leninism or disguised under a red coat, and in essence, it is the same as bourgeois ethnology." (Shi, 1964; Wang, 1998).

At the time, the Ethnological Section of the Department of History in MINZU UNIVERSITY OF CHINA MINZU UNIVERSITY OF CHINA was the only ethnological Chinese teaching institution, but it was renamed the Ethnographical Section in 1964. Ethnology was replaced by "studies of ethnic issues" and actually came to an end in the mainland. Its death would be justified by a formal official sentence. 


\section{Cultural revolution period}

During the period of the Cultural Revolution, from 1966 to 1976, ethnology was very emphatically pronounced a "bourgeois discipline", and teaching and research activities originally in the name of studies on ethnic issues were also completely halted.

The MINZU UNIVERSITY OF CHINA MINZU UNIVERSITY OF CHINA Research Department, the only camp for higher education in ethnology, also suffered from stagnation. The scholars under the department, including Wu Wenzao, Yang Chengzhi, Fei Xiaotong and Lin Yaohua, were sent to the May 7 Cadre School for training. For the purpose of compiling profiles of ethnic minorities and preparing materials on boundaries and ethnic studies, the Research Office was established under MINZU UNIVERSITY OF CHINA MINZU UNIVERSITY OF CHINA, comprising scholars transferred from the cadre school. More specifically, Wu Wenzao, Fei Xiaotong, Xie Bingxin, Kuang Pingzhuang and Li Wenjin were responsible for compilation and translation, while Song Shuhua, Shi Lianzhu, Wang Furen, Wu Heng, Chen Fengxian, Zhu Ning and Huang Shuping were responsible for preparing profiles of ethnic minorities. In December 1974, the Research Office printed the Brief Introduction to Chinese Ethnic Minorities (Draft, 12 volumes in total), edited the internal publication Translated Excerpts on Ethnic Issues, and translated materials (13 issues in total) about foreign nationalities, the history of Russian aggression against China, and Chinese nationals abroad. It also contributed to the country's diplomacy and border negotiations by providing a wealth of information about border areas and ethnic groups.

\section{Ethnology in the new era}

Chinese ethnology ushered in a new era in 1978, after 70 years of twists and turns. Introduced from overseas in the early twentieth century, a relatively complete discipline took its initial shape in the 1920s and 1930s, and rose as a compelling force in international academia with its own characteristics in the 1940s, after a decade-long process of localization and prosperity post-193. After 1949, Chinese ethnologists underwent a thorough transformation with a complete shift towards the Soviet school by severing ties with Western scholars and abandoning Western theories. However, the contact with Soviet academia was cut off after 1960. At this time, "old Chinese ethnology", "Western ethnology" and "Soviet ethnology" were all called "reactionary bourgeois disciplines." In mainland China, ethnology as a discipline came to an end and was then replaced by "ethnic studies". Despite the tireless efforts of ethnologists, ethnology was almost entirely removed from universities and on the brink of disappearance in 1964 or so.

The Government Work Report adopted during the $5^{\text {th }}$ NPC in the spring of 1978 placed ethnology, philosophy, law, economics and history in equal positions, and confirmed ethnology as an independent discipline within the Chinese social sciences. It marked the start of a new life for ethnology in China.

\section{Major changes}

In the 30 years after 1978, Chinese ethnology has undergone major changes in three aspects: 
(1) Rebirth. Ethnology and anthropology started being taught again in dozens of colleges and universities and relevant research institutions were established in most provinces.

(2) End of isolation. Chinese ethnology returned to be part of the international academic society 30 years after the ties with the Western academic world was cut off, especially after a 20-year absence in the international ethnology and anthropology since 1959.

(3) More independence. Chinese ethnology has been constructed as an open academic domain, and lifted out of the stereotypical doctrines based on a certain school or ideology. Before 1949, Chinese ethnology learnt from major Western schools and relied on Western theories. After 1949, it turned to the Soviet model and became part of the Soviet school. Now, it has its own localized academic style, and a Chinese school in ethnology has emerged.

\section{Development stages}

The last 30 years of Chinese ethnology can be roughly divided into the following three periods:

(1) 1980s: restoration and reconstruction. In this decade, China's teaching and research institutions in ethnology and anthropology were restored and rebuilt. More than ten universities set up ethnology and/or anthropology departments or institutions, and dozens offered ethnology and/or anthropology courses. Related journals and columns were also established, and domestic works and teaching materials rolled out, in addition to the translation and publication of all kinds of related foreign books.

(2) 1990s: primary development and enlargement of the research field. In the 1990s, especially in the later 1990s, a large number of social problems arose from China's rapid development after the reform and opening up. The global wave of nationalism after the Cold War also had an impact on the border areas and brought a lot of new ethnic problems. To address these problems, research and explanation from the perspective of ethnology and sociology were required. In this context, the government and society started paying more attention to ethnology and anthropology, and ethnologists became actively involved in the examination of China's current social problems. Therefore, Chinese ethnology achieved fast development and presented preliminary innovative research instead of the introduction of foreign theory and methodology, with research fields extending to almost all existing branches of international ethnology.

(3) 2000s: the golden age of ethnological development. Thanks to the support of the government and society, Chinese ethnology entered a golden age of development, with closer exchanges with its international counterparts in the new century. After nearly 30 years of efforts, Chinese ethnologists have been able to discuss and debate on an equal basis with mainstream international academia, initially fostering distinct characteristics, and producing research findings of top international concern. A Chinese school in ethnology has stood out through its construction as an independent domain.

\section{Progress overview}

The progress made in the last 30 years is briefed below: 


\section{Teaching and research institutions}

The Association of Chinese Ethnology was reconstructed in 1980. Now, it has nearly 2000 members, $45 \%$ of whom are from over 40 ethnic minorities, with three branches for the Han ethnic group, the Hui ethnic group, and visual anthropology. There are a number of local ethnic societies focusing on social and ethnic studies, such as China Southwest Society of Ethnic Groups, Heilongjiang Provincial Institute of Ethnic Studies, Jilin Society of Ethnic Groups, Ethnology Society of Xinjiang Uygur Autonomous Region, Yunnan Society of Ethnic Groups, Guangdong Provincial Institute of Ethnic Studies, Guangxi Institute of Ethnic Studies, Hubei Institute of Ethnic Studies, and Fujian Institute of Ethnic Studies. The societies dedicated to the study of a single ethnic group are also common. Established in 1981, the Society of Chinese Anthropology currently counts 1 thousand members.

The 13 universities for ethnic minorities in China, represented by Minzu University of China (MUC), have mostly set up institutes or departments for ethnological teaching and research. More than 10 universities have integrated ethnology and anthropology into their departments, institutes or specialties, such as Yunnan University, Sun Yat-Sen University, Xiamen University, Lanzhou University, and Peking University. In recent years, more colleges and universities began to offer related courses.

Built on the MINZU UNIVERSITY OF CHINA MINZU UNIVERSITY OF CHINA Research Department, MUC set up the Department of Ethnology in 1983, expanded it to the Institute of Ethnology in 1994, under which there were five departments and labs, and renamed it the Institute of Ethnology and Sociology in 2000. The university established a four-tier teaching and training system in the 1980s, covering undergraduate, graduate, doctoral and post-doctoral stations, and currently has more than 800 undergraduate, graduate and doctoral students. Their research concerns include China's ethnic society and culture, world's peoples, ethnological theory and methodology, applied ethnology, historical ethnology, ethnic economy, ethnic theory and policy, ethnic relations and identification, ethnology history, ecological ethnology, ethnic heritage, archeology, and physical anthropology. MUC boasts the strongest faculty and most comprehensive research scope among such teaching and research institutions.

Yunnan University, Peking University, Lanzhou University, Xiamen University and Sun Yat-Sen University, as well as 12 other universities with considerable strength in ethnology and anthropology have made outstanding achievements in the theory and methodology of ethnology (anthropology), historical ethnology, urban anthropology, and local ethnic studies. Nearly ten of them offer doctoral courses in anthropology or ethnology.

In the system of social sciences, the Institute of Ethnology and Anthropology and the Department of Ethnology of the Graduate School of CASS are considered the most prominent research institutions outside the college system.

\section{Basic theoretical research and applied research}

Research on the theory and methodology of ethnology (anthropology)

"Our scholars need 'catch-up work' to make up for the weak disciplinary foundation. In a changing world, can the methodology we have mastered adapt to the object of research? If yes, can we put forward in-depth historical views?" commented Fei Xiaotong while talking about the status of Chinese sociology, ethnology and anthropology (Fei, 2000). 
The weak disciplinary foundation mentioned by Fei mainly refers to the lack of accumulation in theory and methodology over the years, lack of comprehension and absorption of the relevant outcomes of international academia, and lack of theoretical innovation. From a theoretical point of view, what we are doing now is "catch-up" work. Domestic ethnologists mainly study, introduce and follow up the theories of international ethnology (anthropology) in a variety of ways. In terms of teaching and research, the work is mostly concentrated on the presentation, translation and review of foreign classic theories and writings, dynamic research and post-modern theoretical trends (Ember, et al., 1988).

During the early restoration of ethnology and anthropology in the 1980s, the translation work was focused on general theoretical works and textbooks, such as the People and Culture series published by Liaoning People's Publishing House, and on introductory articles, such as Collection of Translated Papers on Ethnology complied by the Institute of Ethnic Studies of CASS and MINZU UNIVERSITY OF CHINA MINZU UNIVERSITY OF CHINA Ethnic Research Institute. In the 1990s, Chinese scholars began to write and publish professional textbooks, while shifting the focus of translation to classic works of the 1950s, such as the first five books of the Modern Anthropological Classics series published by Huaxia Publishing House in 2002 (Malinowski, 2002). In recent years, Chinese scholars have tended to update foreign contemporary works, mainly books and papers published in the past decade. The papers in Western journals of ethnology and anthropology and their Chinese versions are almost simultaneously available, owning to more frequent and in-depth academic exchanges. There are also reviews of Western ethnological works (Bao, 1995; Dai, 2001; Xia, 1997; Liu, 2001).

These efforts in the last three decades represent the large-scale systematic introduction of Western ethnology (cultural anthropology) in both theory and methodology, following the upsurge of translations in the early twentieth century. Meanwhile, progress has been made in the localization of theory and methodology, by combining ethnology with China's national conditions and the history and characteristics of Chinese ethnology. For example, in-depth discussions were carried out on the definition of "ethnic group" and "ethnic" identification and relations, of which an influential view is the theory from culturalization to politicization, from A New Perspective to Examine Ethnic Relations: Depoliticization of Ethnic Minority Issues (Ma, 2004a, b). New interpretations on the definition of "ethnic" and "ethnic group" have been put forward based on the comparison of theories of Chinese and Western scholars. With respect to methodology, field surveys are integrated into history and ethnology, such as contemporary social and cultural studies of ethnic groups through oral history (Ding and $\mathrm{Hu}, 2003$ ), historical and ethnological combination, and qualitative analysis in ethnology combined with quantitative analysis in sociology (Yang, 2003a, b, c, d). In recent years, a number of writings on the methodology of ethnology and anthropology, as well as fieldwork were published (Rong, 1999; Song and Bai, 1998; Wang, 2004; Ye, 2002).

\section{Applied research in ethnology}

The fundamental way to develop Chinese ethnology is closely linked with Chinese society. It is supposed to correctly explain the social reality of all ethnic groups from the perspective of ethnology and anthropology and serve for China's social development. In 
this combination, theory and methodology can be innovatively localized through the analysis of a large number of first-hand information. Compared with theory and methodology, Chinese ethnology has witnessed more remarkable results in applied research, mainly on issues concerning development, environment and ethnic relations. Among them, the most influential is the Investigative Study on Economic and Social Development of Small-Population Ethnic Groups in China, jointly launched by MUC, PKU and SEAC in 2000. Its Phase I Report was completed and submitted to the State Council in 2002, based on which the State Council issued the No. 44 Document, granting billions of yuan to support the development of 22 small ethnic groups.

With regard to ethnic development, it is worth noting that in recent years, scholars have begun to re-examine the "development" we need, and to explore the pathways in the context of modernization and western development (Yu, 2003; Gao, 2004; Shi, 2004). Intensively discussed topics also include development sustainability, economic development in harmony with traditional culture, and environmental protection in the process of modernization and western development (Li, 2003; Yang, 2003a, b, c, d; Liang, 2005). These studies have significant implications for society, government and local communities, as well as ethnic groups.

The research on ethnic relations has also resulted in an abundance of published outcomes, covering conflicts between different peoples and cultures on a global scale (Fan, 2003), conflicts between globalization and multi-ethnic culture (Wang, 2004), and the impact of intermarriage and language on ethnic relations (Ma, 2004a, b).

\section{Achievements and innovation}

In recent years, China ethnology has yielded very fruitful results in terms of basic research and applied research. A part of the outcomes revises and develops the traditional theories of general concern in the international ethnological and anthropological community, while another part further enriches and highlights the localized style of Chinese ethnology both in theory and methodology.

\section{Gradual formation of branches}

Through many years of research efforts and data accumulation, a number of branches of ethnology and anthropology have been established. This is reflected in the publication of a series of textbooks and books, as well as the provision of corresponding courses in ethnology and anthropology by colleges and universities. Specifically, the increasingly evident and different perspectives in theory and methodology not only facilitate in-depth research, but also stimulate the establishment of societies and academic conferences dedicated to different discipline branches.

The teaching materials, newsletters and books published in recent years mainly cover the following branches: economic anthropology (Shi, 2002), visual anthropology (Society of Visual Anthropology. Introduction to Visual Anthropology 2003; Society of Visual Anthropology. Introduction to Visual Anthropology, 1996-2004; Yang, 2003a, b, c, d) physical anthropology (Zhu, 2004), urban anthropology (Zhou, 1997; Ruan, 1991; Zhou, 1991; China Society of Urban Anthropology edited, 1990-2004), anthropology of religion(Jin, 2001; Mou, 2003), applied anthropology (Shi, 1996; Xie, 1990), youth anthropology, and ecological anthropology (Cao et al., 1991). There are also published works and translations 
on legal anthropology and feminist anthropology (Donald. L. Hardesty, 2002; Liu, 1998; Xiao et al., 1998; Zhou, 2002; Liu, 2001). Influential research findings can also be found in the historical, aesthetic, educational, migrant, rural and medical fields of anthropology.

\section{Impact on the traditional theories of international ethnology}

Chinese ethnology and anthropology are Western "imports" that have experienced ups and downs in their short time of development. They do not have adequate academic achievements and research teams, or occupy a high position in the international academic community. However, with a significant improvement of their level of research, the research findings have increasingly drawn international attention in recent years, some of which impact international ethnology and anthropology by shaking traditional theories. Noteworthy is the study of the marriage system (Cai, 1997), which aroused the interest of European and American circles of ethnology and anthropology. The works of Cai Hua, once published, have been highly commented and concerned by world famous anthropologists, such as Claude Lévi-Strauss (France), Rodney Needham (UK), and Clifford Geertz (US) (Clifford Geertz, 2002).

The research achievements of Chinese scholars in the study of the marriage system and the Mosuo people in Yunnan are the result of decades of data accumulation. In the 1950s and 1960s, the old generation of Chinese ethnologists conducted an investigation on the Mosuo people and published a number of monographs. (Yan and Song, 1981) Despite different interpretations of this problem at home and abroad, (Han, 2003) this study itself demonstrates that the Chinese ethnological academia has increasingly delivered world-class outcomes after decades of accumulation, and contributed to the development of theories in international ethnology.

\section{Outstanding application results in combination with practices}

Practical applications highlight the traditional feature of Chinese ethnology, which gives priority to applied research on social issues over basic research. Especially in the past 30 years, the research has extended into almost all social and ethnic issues arising from the country's great development and change. The research topics include the relationship between economic globalization and local ethnic cultural diversity, ethnic relations and conflicts, religious trends in the context of modernization, ethnic minority areas in western development, traditional culture and coordinated economic development of ethnic groups, nationalism and ethnic schisms, urban floating minority population, ethnic education, ethnic languages and the relationship with standard Chinese, and ethnic policies.

The research findings are published in the form of monographs, papers and reports, and in most cases, integrated into internal government reports at all levels as reference for policy adjustment and formulation. A typical case is the aforementioned Investigative Report on Economic and Social Development of Small-Population Ethnic Groups in China, which was promptly adopted by the State Council.

\section{Combination of history and ethnology}

In spite of their weak foundation, Chinese ethnology and anthropology have the advantage of the voluminous historical literature left in the 5000-year-long history of Chinese civilization. In China, history is the oldest and most profoundly investigated subject. 
Drawing on the methods and traditions of this subject and taking full advantage of rich historical literature has been a time-honored privilege for Chinese anthropology and ethnology. It is reflected in a lot of the works and papers on ethnology published in recent years. Historical documents are referred to in the background introduction of communities, ethnic groups and populations, but also used to probe into the historical factors of current social and cultural phenomena, thereby giving more accurate and indepth explanations. A prominent example comes from the research on the oral history of ethnology, which is different from the Western approach. Relying on historical documents and literature investigation, Chinese scholars mostly integrate literature in to their research to correct the deviation of oral history and explain oral content, which makes Chinese oral history research unique (Ding, 2003a, b).

\section{Emergence of the Chinese ethnological school}

As it enters the twenty-first century, Chinese ethnology is significantly accelerating its pace and embracing the golden age of its development. First, society and the government are giving more attention and support to ethnology. Two Chinese ethnologists were invited to deliver a speech at the 16th collective study session of the CPC Central Committee Politburo on October 22, 2004. After that, General Secretary Hu Jintao delivered a speech requiring the whole Party to study ethnology, anthropology and ethnic theory. It was the first time in the last five decades that China's top leaders attached such importance to ethnology. This important event in the development of Chinese ethnology symbolized the achievement of an elevated status for the discipline.

Meanwhile, Chinese ethnology and anthropology have further improved their impact on the international academic community. In July 2000, hundreds of ethnologists and anthropologists from more than 40 countries around the world attended the mid-term congress of the International Union of Anthropology and Ethnology (IUAE) in Beijing. This represented a milestone of Chinese ethnology and anthropology in their process towards their full participation in international academic activities. In order to further strengthen international exchanges and enhance its international influence, the China Union of Anthropology and Ethnology (CUAE) joined the competition with the Italian Society for Ethnology and Anthropology. In 2002, the IUAE Board decided that the $16^{\text {th }}$ World Congress would be held in China by CUAE in 2009. This meant that Chinese ethnology and anthropology had evolved into an important force within the international community.

To showcase research findings, the Preparatory Committee comprising of universities and academic organizations was set up by CEAC and CUAE in 2004, and through its coordination, the meeting agenda and branch-specific topics were confirmed in 2005. While scholars were actively engaged in the preparation of relevant topics, the Preparatory Committee organized the translation of domestic representative papers and monographs into English, to help the international community understand Chinese ethnology and anthropology. At present, the World Congress is scheduled for July 2009 in Kunming, Yunnan Province, and has over 2000 registered foreign participants. Yunnan Provincial Government and Yunnan University are currently making active preparations for this event.

Based on the research achievements accumulated over the past century, especially the last three decades, a Chinese ethnological school has emerged, referred to as 
historical functionalism by Qiao Jian, and represented by Fei Xiaotong (Qiao, 2008). It is believed that adherence to and application of Marxism is another feature of Chinese ethnological school.

\section{Endnotes}

${ }^{1}$ Lin Shu, Wei Yi translated Ethnology, which originally translated by British scholar J. H. Loewe from Voelkerkunde (ethnology in German) authored by Michael Haberland.

${ }^{2}$ The Charter of Imperial University of Peking, promulgated by the Educational Department of the Qing Dynasty in 1903, specified for the first time "ethnography" which is now called "ethnology", as a university course.

Competing interests

I declare that I have no competing interests.

\section{Publisher's Note}

Springer Nature remains neutral with regard to jurisdictional claims in published maps and institutional affiliations.

Received: 8 May 2017 Accepted: 8 September 2017

Published online: 18 December 2017

References

Bao, Xiaolan, editor-in-chief. 1995. Review of Western Feminism. Beijing: Joint Publishing; Social Science in China Press. Anthropology Trend. Beijing: Social Sciences Academic Press, 2000.

Cai, Hua. 1997. A society without fathers and husbands: French version. Paris: France University Press.

Cao, Xing, et al. 1991. Youth anthropology. Changchun: Jilin People's Publishing House.

Chen, Yongling, Wang, Xiaoyi. 1981. Chinese Ethology in Early 20th Century. Study of Ethnology: Volume 1. Beijing: The Ethnic Publishing House.

China Society of Urban Anthropology edited. 1990-2004. Newsletter of China Society of Urban Anthropology.

Dai, Yixuan. 2001. History of Western Ethnology. Beijing: Social Sciences Academic Press, 2001; Xia Jianzhong. Theory School of Cultural Anthropology. Beijing: China Renmin University Press, 1997; Liu Ni. Western Feminist Studies. Beijing: Social Sciences Academic Press.

Ding, Yizhuang. 2003a. Oral tradition and oral history. Journal of Guangxi University for Nationalities: Philosophy and Socialsciences.

Ding, Yizhuang. 2003b. Oral tradition and oral history. Journal of Guangxi University for Nationalities: Philosophy and Social Science (3)

Ember, Carol R. et al. 1988. Cultural Anthropology. Du Shanshan, Translated. Shenyang: Liaoning People's Publishing House; F. Plog, et al. Cultural Evolution and Human Behavior. Wu Aiming, et al., Translated. Shenyang: Liaoning People's Publishing House, 1988.

Engels, Friedrich. 1972. Origin of the Family, Private Property and the State: Preface to the First Edition. Selected works of Marx and Engels: Volume IV. Beijing: People's Publishing House.

Fan, Ke. 2003. Civilization conflicts and coexistence with differences. Journal of Guangxi University for Nationalities: Philosophy and Social Sciences 5.

Fei, Xiaotong. 1985. Five decades of study in sociology, 70. Tianjin: Tianjin People's Publishing House.

Fei, Xiaotong. 1986. Peasant life in China, 1-4. Nanjing: Jiangsu People's Publishing House.

Fei, Xiaotong. 2000. New challenges facing Chinese anthropology in the 21st century. Journal of Guangxi University for Nationalities: Philosophy and Social Sciences 5: 1.

Fei, Xiaotong, Lin, Yaohua. A Few Tasks in Ethnology Posed by Current Ethnic Work. Published in People's Daily in August 1956, later in Issue 6 of the Collected Papers on China Ethnic Studies in 1957.

Gao, Yongjiu. 2004. Urban spatial structure in northwest ethnic regions. Journal of South-Central University for Nationalities: Humanities and Social Sciences (6).

Geertz, Clifford. 2002. Visit - review of A Society Without Fathers and Husbands: The Na of China of Hua Cai. Ethnic Studies 1.

Gu, Dingguo. 2000a. Unofficial history of Chinese anthropology, 157. Beijing: Social Science Academic Press.

Gu, Dingguo. 2000b. Unofficial history of Chinese anthropology, 158. Beijing: Social Science Academic Press.

Han, Junkui. 2003. Comparison and analysis of two texts about cohabitation of the Na people. Journal of South-Central University for Nationalities: Humanities and Social Sciences 6.

Hardesty, Donald L. 2002. Ecological Anthropology. Guo Fan, et al., Translated. Beijing: Cultural Relics Press.

$\mathrm{Hu}$, Hongbao. 2003. Fieldwork and literature of oral history. Journal of Guangxi University for Nationalities: Philosophy and Social Sciences 3.

Hu, Hongbao. 2006. History of Chinese anthropology. Vol. 103. Beijing: China Renmin University Press.

Jin, Ze. 2001. Introduction to anthropology of religion. Beijing: China Religious Culture Publisher.

Kang, Youwei. 1987. Reply to Mr. Zhu Rong. The Complete Works of Kang Youwei: Volume 1. Shanghai: Shanghai Ancient Books Publishing House. 1034-1043. 
Li, Yiyuan. 2003. Environment, ethnic groups and culture. Journal of Guangxi University for Nationalities: Philosophy and Social Sciences (2).

Liang, Jingyu. 2005. "Tourism and preservation of ethnic culture and ecological environment" []]. Journal of Guangxi University for Nationalities: Philosophy and Social Sciences 1.

Liang, Zhaotao. 1964. Anthropology, archeology and ethnology and the relationship with class struggle. Academic Research (6). Lin, Yaohua. 1984. Primitive social history. Vol. 32. Beijing: Zhonghua Book Company.

Liu, Shusong editor-in-chief. Economy, culture and environment. Beijing: Central University Publishing House, 1998.

Liu, Ni. 2001. Western feminist studies. Beijing: Social Sciences Academic Press.

Ma, Changshou. 1947. Anthropology in border governance of China. Public Opinions on Border Governance 3.

Ma, Rong. 2004a. A new perspective to examine ethnic relations: Depoliticization of ethnic minority issues. Journal of Peking University: Philosophy and Social Science (6).

Ma Rong. 2004b. "Language Use and Ethnic Relations". Northwest Ethic Studies; (1); Liang Maochun. "Factors Affecting Intermarriage". Northwest Ethic Studies. 2004 (3).

Malinowski, Bronislaw. 2002. A Scientific Theory of Culture and Other Essays. FeiXiaotong, Translated; Raymond Firth. Human Types. FeiXiaotong, Translated; Radcliffe Brown. Method in Social Anthropology. Xia Jianzhong, Translated; Bronislaw Malinowski. Argonauts of the Western Pacific.Liang Yongjia, Translated; Evans Pritchard. The Nuer. Chu Jianfang, et al., Translated. Beijing: Huaxia Publishing House.

Maurice, Freedman. 1962. Sociology in China: A brief survey. The China Quarterly 10: 166-173.

Mou, Zhongjian 2003. editor-in-chief. Religion and ethnic group. Beijing: China Religious Culture Publisher.

Qiao, Jian. 2008. Tentative analysis of historical functionalism of FeiXiaotong. Yang Shengmin, editor-in-chief. Selected works on Chinese anthropology and ethnology in the century. Beijing: Intellectual Property Publishing House.

Research Department of the Central University for Nationalities. 1955. Compilation of translated ethnological works: Afterword:(4).

Rong, Guanqiong. 1999. Anthropological methodology. Nanning: Guangxi Nationalities Publishing House.

Ruan, Xihu. 1991. Urban Anthropology. Beijing: Huaxia Publishing House.

Shi, Jin. 1964. Question Ethnology: Talking with Mr. Yang Kun. Academic Research;(2), quoted from Wang Jianmin, et al. History of Chinese Ethnology: Volume II. Kunming: Yunnan University Press, 1998: 218.

Shi, Yilong. 1996. Applied anthropology. Xiamen: Xiamen University Press.

Shi, Lin. 2002. Economic anthropology. Beijing: Minzu University Publishing House.

Shi, Yilong. 2004. Economic convergence and ideographic cultural specialization: Dual nature of ethnic minority development in the process of Chinese modernization. The Ideological Front 4.

Skinner William G. ed. 1979. The study of Chinese society. Stanford University Press: Part five.

Society of Visual Anthropology. 1996-2004. Visual anthropology newsletter.

Song, Shuhua, and Zhensheng Bai. 1998. Ethnological theory and methodology. Beijing: Central University Publishing House Wang Ningsheng. Investigation to Cultural Anthropology. Beijing: Cultural Relics Press, 2002.

Song, Shuhua, et al. 2004. Five decades of Chinese ethnology. Beijing: People's Publishing House 245.

Su, Keqin. 1958. Replace white flag with red flag in ethnology. Ethnic Studies 2.

Wang, Feng. 2004. Challenges in globalization and resilience of ethnic culture. Northwest Ethic Studies 3.

Wang, Jianmin, et al. 1998. History of Chinese ethnology: Volume II. Kunming: Yunnan University Press 228.

Wu, Wenzao. 1942. Introduction to border politics. Public Opinions on Border Governance 1: 5-6.

Xia, Jianzhong. 1997. Theories of culture anthropology. Beijing: University of Chinese. People Publishing House.

Xiao, Chenyang, et al. 1998. Translated. Environment and Society. Tianjin: Tianjin People's Publishing House.

Xie, Jian. 1990. Theory and practice: Introduction to contemporary applied anthropology. Chengdu: Sichuan People's Publishing House.

Xin, Liu. 2004. Past and present: Two moments in history of Chinese anthropology. Shinji Yamashita Edited. The making of anthropology in east and Southeast Asia. New York: Berghahn Books: 152-183.

Yan, Ruxian, Song, Zhaolin. 1981. Matriarchal System of YongningNaxi Ethnic Group. Kunming: Yunnan People's Publishing House, 1991; Zhan Chengxu. "Tentative Analysis of Matrilineal and Patrilineal Coexistence in YongningNaxi Ethnic Group". Social Sciences in China (4).

Yang Jianxin. 2003a. Edited. Visual Dialogue. Beijing: The Ethnic Publishing House.

Yang, Shengmin. 2003b. Environment and family: Characteristics of Tajik culture. Journal of Guangxi University for Nationalities: Philosophy and Social Sciences 2.

Yang Shengmin. 2003c "Methods of ethnological studies: Field investigation and ethnography". Guangming daily, (4).

Yang, Shengmin. 2003d. Characteristics of social Organization in Arid Environment. Environment, Development and Culture in Asia-Pacific Societies 6: 120-129.

Ye, Zhicheng. 2002. Research methodology and research report. Beijing: China Textile Press.

Yu, Bromley. ed. 1974. Soviet Ethnology and Anthropology Today: Part I. Paris: Mou-ton. The Hague; Song Shuhua ed. Fifty Years of Chinese Ethnology. Chapter 6, Section 2.

Yu, Changijiang. 2003. Hezhe ethnic Group in Modernization Process: Culture or mode of production. Journal of Guangxi University for Nationalities: Philosophy and Social Sciences 2.

Zhang, Zhidong 1898. Mastery XIII. Zhang Zhidong. QuanXuePian (Exhortation to Study), Hunan-Hubei Academy, 24th Year of Guangxu.

Zhou, Daming. 1991. Three Questions on Urban Anthropology. Guangzhou: Sun Yat-Sen University Press; Li Dezhu. Urban Anthropology and Border Urban Theory. Beijing: China Aerospace Press, 1996.

Zhou, Daming. 1997. Modern Urban Anthropology. Guangzhou: Sun Yat-Sen University Press; RuanXihu. Urban Anthropology. Beijing: Huaxia Publishing House, 1991.

Zhou, Yong. 2002. Legal theory of minority rights. Beijing: Social Sciences Academic Press.

Zhu, Hong. 2004. Physical anthropology. Beijing: Higher Education Press. 